\title{
PROGRAMA DE PROTEÇÃO AO EMPREGO: CINQUENTA ANOS DEPOIS, A HISTÓRIA SE REPETE
}

\author{
Almiro Eduardo de Almeida* \\ Kleber Correa da Silveira***
}

\begin{abstract}
RESUMO
O Programa de Proteção ao Emprego foi criado por uma medida provisória que, após passar pelo Congresso Nacional, restou convertida na Lei no 13.189/2015, que autoriza a redução salarial mediante a correspondente redução da jornada de trabalho. Cinquenta anos antes, fora aprovada a Lei no 4.923/1965 que, ainda em vigor, dispõe sobre o mesmo assunto. 0 presente artigo faz uma análise crítico-comparativa das duas leis, a fim de demonstrar que a norma editada no atual regime democrático, consegue ser mais prejudicial aos trabalhadores do que aquela editada em plena ditadura. A comparação das normas é precedida de uma breve análise dos dois momentos históricos quanto a seus aspectos econômico, político e social, com o intuito de compreender o que levou às suas edições. Por fim, sustenta que os dispositivos da Lei $n$ o $13.189 / 2015$ que forem mais
\end{abstract}

* Juiz do Trabalho Substituto no Tribunal Regional do Trabalho da 4⿳亠丷a Região. Professor de Graduação no Centro Universitário Metodista - IPA. Especialista em Direito do Trabalho pela Universidad de la República Oriental del Uruguay. Mestre em Direitos Sociais e Políticas Públicas pela Universidade de Santa Cruz do Sul - UNISC. Doutorando em Direito do Trabalho pela Universidade de São Paulo - USP. Membro-pesquisador do Grupo de Pesquisa Direitos Humanos, Centralidade do Trabalho e Marxismo. Membro-pesquisador do Núcleo de Estudos sobre Teoria e Prática da Greve no Direito Sindical Brasileiro Contemporâneo. Coordenador do Grupo de Pesquisa em Direito do Trabalho do Centro Universitário Metodista - IPA.

** Graduando em Ciências Jurídicas e Sociais pelo Centro Universitário Metodista - IPA. Membro-pesquisador do Grupo de Pesquisa em Direito do Trabalho do Centro Universitário Metodista - IPA. 
prejudiciais aos trabalhadores do que os da Lei no 4.923/1965 não podem ser aplicados por violação à Constituição Federal.

PALAVRAS-CHAVES: Programa de Proteção ao Emprego; Redução Salarial; Redução da jornada de trabalho.

\section{ABSTRACT}

The Employment Protection Program was created through a provisional measure and, after passing through Congress, became Law No. $13.189 / 2015$, which authorises pay cuts by a corresponding reduction in working hours. Fifty years ago, law No. 4.923/1965 on the same subject was approved and is still in effect. This article is a judicious and comparative analysis of the two laws to demonstrate that the rule published in the current democratic regime can be more harmful to workers than the one published during the dictatorship. The comparison is preceded by a brief analysis of the two historical moments in their economic, political and social aspects, as means to understand what led to their issuing. Finally, it argues that provisions of Law No. 13.189/2015 that are more harmful to workers than those of Law No. 4.923/1965 cannot be applied, as they violate the Federal Constitution.

KEYWORDS: Protection Program Employment; Salary Reduction; Reduction of working hours.

Quando querem transformar

Dignidade em doença, Quando querem transformar Inteligência em traição, Quando querem transformar

Estupidez em recompensa, Quando querem transformar

Esperança em maldição... Legião Urbana, 1965 (Duas Tribos)

\section{INTRODUÇÃO}

Citando uma passagem de Hegel, Marx refere que a história se repete, a primeira vez como tragédia, a segunda como farsa. Em 23 de Dezembro de 1965, foi decretada pelo Congresso Nacional e sancionada por um dos articuladores do Golpe Militar e primeiro ditador do Regime, uma lei que autoriza a redução 
salarial mediante correspondente redução da jornada de trabalho. Cinquenta anos depois, em 06 de julho de 2015, é adotada, por uma presidente vinculada ao Partido dos Trabalhadores, uma medida provisória que, após ser convertida em lei, pelo Congresso Nacional, em pleno regime democrático, consegue ser ainda pior.

No presente artigo, nos propomos a fazer uma análise crítico-comparativa dos dois textos normativos, precedida de uma breve análise dos dois momentos históricos quanto a seus aspectos econômico, político e social. Momentos históricos e textos legislativos distantes cronologicamente por cinquenta anos, mas que se mostram muito próximos no que diz respeito à ideologia que predominantemente os informa, como se verá.

Sendo o trabalho um dos mais importantes pilares da sociedade, e, estando o Brasil inserido no que se convencionou chamar de capitalismo tardio, em uma economia marcada pela globalização, resta-nos buscar compreender estas mudanças que acabam atingindo os dois pilares fundamentais da principal relação de produção da sociedade contemporânea: jornada de trabalho e salário.

\section{COMPARAÇÃO DOS CONTEXTOS ECONÔMICO, PO- LÍTICO E SOCIAL DE 1965 E DE 2015.}

Antes de analisarmos os textos normativos, mostra-se indispensável um estudo sobre o contexto econômico, político e social dos momentos históricos em que foram editados.

Se hoje usa-se a roupagem da crise econômica e da ameaça do desemprego para justificar a flexibilização dos direitos trabalhistas, o mesmo não pode ser alegado quanto à época ditatorial. Apesar da alta inflação o Brasil vivia uma grande ascensão econômica nas décadas de 1950 e $1960^{1}$. No tocante a infraestrutura o

\footnotetext{
A taxa anual da inflação que, em 1955 era de 19,1\%, em 1959 atingiu 52,1\%. Nos anos seguintes teve uma pequena queda, voltando a subir em 1963, quando atingiu 79\%. MATOS, Marcelo Badaró. Trabalhadores e sindicatos no Brasil. 1 ed. São Paulo Expressão Popular, 2009 p. 91.
} 
setor energético assistiu a um aumento da produção de energia elétrica na casa dos 50\% entre 1955 e 1961. A produção de petróleo também estava em plena expansão saltando de 2 milhões de barris por ano em 1955 para 30 milhões em 1960². Nessa última década, a taxa de emprego mantinha-se estável, mostrando-se, inclusive, crescente em relação às décadas de 1940 e $19500^{3}$ Até 1955, praticamente não se produziam automóveis no Brasil. Apenas em 1960, foram produzidos mais de 130 mil veículos em solo nacional. 0 setor automobilístico empregava então mais de 130 mil operários ${ }^{4}$. O PIB do país passara de 15,1 bilhões em 1960 para 23 bilhões em $1963^{5}$. Essa ascensão econômica não se limitava ao Brasil, mas atingia praticamente todos os países capitalistas. Não à toa, o período compreendido entre o início da década de 1940 e o início da década de 1970 ficou conhecido como "os anos dourados do capitalismo" em todo o ocidente. ${ }^{6}$

Por outro lado, quanto ao aspecto político, o país vivia um de seus mais conturbados momentos. Após Jânio Quadros renunciar à Presidência de República, em 25 de agosto de 1961, devido a "forças terríveis", ou "forças estranhas", conforme a versão do

2 MATOS, Marcelo Badaró. Trabalhadores e sindicatos no Brasil. 1 ed. São Paulo Expressão Popular, 2009 p. 90

3 FASUTO, Boris. O Brasil Republicano: economia e cultura (1930-1964). 3 ed. Rio de Janeiro: Bertrand Brasil, 1995 p. 124.

4 MATOS, Marcelo Badaró.Trabalhadores e sindicatos no Brasil. 1 ed. São Paulo Expressão Popular, 2009 p. 90.

5 Disponível em https://www.google.com.br/publicdata/explore?ds=d5bncppjof8f9_\&met_y=ny_gdp_mktp_cd\&idim=country:BRA:ARG:IND\&hl=pt\&$\mathrm{dl}=\mathrm{pt} \#$ !ctype $=\mathrm{l} \&$ strail=false $\& \mathrm{bcs}=\mathrm{d} \&$ nselm $=$ h\&met_y=ny_gdp_mktp_cd \&scale_y=lin\&ind_y=false\&rdim=region\&idim=country:BRA\&ifdim=region\&tstar$\mathrm{t}=-286927200000 \&$ tend $=-160696800000 \& \mathrm{hl}=\mathrm{pt} \& \mathrm{dl}=\mathrm{pt} \& \mathrm{ind}=$ false. Acesso em $28 / 11 / 2015$.

6 Como não existe capitalismo sem crise, é importante destacar que, mesmo durante esses "anos dourados", houve inúmeras pequenas crises na economia internacional, como as dos anos 1949, 1953, 1958, 1961, 1970, até, finalmente, a grande crise dos anos de 1973 e 1975. MANDEL, Ernest. A crise do capital: os fatos e sua interpretação marxista. São Paulo: Ensaio; Campinas, SP: Editora da Universidade Estadual de Campinas, 1990, p. 9. 
Repórter Esso, que ficou notória na historiografia brasileira, João Goulart assumiu o poder. ${ }^{7} \mathrm{~A}$ ascensão do vice-presidente inaugura um período de sucessivas crises políticas. Na ocasião da renúncia, Jango encontrava-se na China e havia sérias suspeitas (infundadas, como se viria a saber mais tarde) de envolvimento com comunistas. Chefiada pelo gaúcho Leonel Brizola, a campanha da legalidade fez com que Jango assumisse o poder, mas não sem acolher uma proposta conciliatória de adoção do sistema parlamentarista de governo. Tancredo Neves, Brochado da Rocha e Hermes Lima sucederam-se no cargo de primeiro ministro em pouco mais de um ano de vigência do sistema. Já em janeiro de 1963, mediante um plebiscito, retorna o sistema presidencialista. Jango volta a acumular os cargos de chefe de estado e chefe de governo. Com sua ascensão ao poder, inicia-se o processo para uma série de reformas, conhecidas como Reformas de Base - medidas econômicas e sociais de caráter intervencionista que, conforme esclarece o historiador Boris Fausto, tinham por finalidade "modernizar o capitalismo e reduzir as profundas desigualdades sociais do país", e não implantar no Brasil um sociedade comunista ou socialista. ${ }^{8}$

Ao populismo característico do governo de João Goulart, somam-se uma série de mobilizações e pressões sociais coordenadas principalmente por entidades sindicais. Em aliança com o governo, a ideia era a aprovação das denominadas Reformas de Base. Fausto relata que, enquanto no ano de 1958 foram registrados apenas 31 movimentos grevistas, no ano de 1963

\footnotetext{
Segundo a hipótese mais provável, a renúncia de Jânio Quadros teria sido o blefe mais famoso da história brasileira: o presidente esperava que, com a ameaça de renúncia, obtivesse apoio popular e maiores poderes de governança, livrando-se dos entraves do Congresso Nacional e dos partidos políticos opositores. Como se sabe, não foi o que ocorreu. FASUTO, Boris. História concisa do Brasil. 1 ed. São Paulo: Universidade de São Paulo, 2002, p. 243. 8 FASUTO, Boris. História concisa do Brasil. 1 ed. São Paulo: Universidade de São Paulo, 2002, p. 246.
} 
eles chegaram a $172 .{ }^{9}$ Esses números indicam bem o avanço das mobilizações sociais do período.

Em 31 de março de 1964, com o país em plena ascensão econômica e alta mobilização social, ocorre o Golpe de Estado que coloca os militares no poder. 0 Golpe é dado como uma resposta à tentativa de implantação das reformas, vistas pelos setores mais reacionários da sociedade como uma tentativa de implantação de um regime comunista no Brasil. Em 27 de outubro do ano subsequente o então Ditador Castello Branco decreta o AI-2 estabelecendo, dentre outras medidas, eleições indiretas, intervenção federal nos estados e municípios, cassação dos partidos políticos e perda de direitos políticos dos opositores do regime.

Menos de dois meses depois, o Congresso Nacional decretaria e o ditador Castello Branco sancionaria a Lei n. 4.923, de 23 de dezembro de 1965. Caracterizando-se como uma das primeiras medidas flexibilizadoras do Direito do Trabalho no Brasil, e mesmo na América Latina, a lei permite uma redução geral e transitória dos salários mediante negociação coletiva. Menos de um ano depois, em 1966, outra lei, conhecida por todos os operadores do Direito do Trabalho, transformaria a estabilidade decenal prevista na CLT em mera ficção jurídica, ao atribuir ao empregado a possibilidade de optar pelo sistema celetista ou por um fundo que, na verdade, apenas servia para lhe retirar o direito à estabilidade no emprego. Diante de uma economia favorável e de estabilidade no emprego, é como se a lei de 1965 viesse para solucionar o problema do desemprego que seria criado pela lei de 1966.

Por incrível que pareça, o golpe de misericórdia na proteção dos trabalhadores contra a despedida arbitrária ou sem justa causa se deu com a Constituição Federal de 1988, ou melhor, com a interpretação que se lhe atribuiu. Logo após a promulgação da Constituição, que na verdade estendeu a todos os trabalhadores

9 FASUTO, Boris. História concisa do Brasil. 1 ed. São Paulo: Universidade de São Paulo, 2002, p. 243. FASUTO, Boris. História concisa do Brasil. 1 ed. São Paulo: Universidade de São Paulo, 2002, p. 247. 
o direito ao FGTS, passou-se a interpretá-la no sentido de que o fundo universal teria vindo em substituição total da estabilidade decenal. Assim, a estabilidade celetista não haveria sido recepcionada pela nova Constituição, muito embora o texto constitucional nada referisse nesse sentido. Ao contrário, a Constituição estabeleceu como primeiro direito fundamental dos trabalhadores, "relação de emprego protegida contra a despedida arbitrária ou sem justa causa" (Art. 7ํㅡ, inciso I), "além de outros que visem à melhoria de sua condição social" (Art. 7ํㅜ caput).

A história segue seu curso. Depois de um período de forte crescimento econômico-social que teve início nos anos $2000^{10}$, uma crise mundial atingiu duramente os países capitalistas do norte em meados de 2008. 0 governo brasileiro então tomou algumas medidas no sentido de incentivar a retomada do crescimento econômico, reduzindo os impostos do setor automobilístico, eletrodoméstico e da construção civil, todos grandes incorporadores de força de trabalho. Ocorreu com isto uma expansão do mercado interno que acabou compensando a retração do mercado externo.

Em 2015, o Brasil voltou a sofrer com a instabilidade econômica, afetado novamente pela crise econômica mundial e principalmente pela crise política instaurada no país, após sucessivos escândalos de corrupção. Apesar das manifestações de junho de 2013 - carregadas com o simbolismo de um movimento popular por renovação política e avanço dos direitos sociais, que nos faz lembrar do emblemático ano de 1963 — , o resultado das urnas revelou uma guinada em direção oposta. Em um movimento dialético muito semelhante ao de 1964, parlamentares conservadores

10 O PIB no Brasil passou de 508,7 bilhões em 2002 para 2,6 trilhões em 2011, foi o crescimento mais exponencial desde que o índice passou a ser utilizado. Disponível em https://www.google.com.br/publicdata/explore?ds=d5bncppjof8f9_\&met_y=ny_gdp_mktp_cd\&idim=country:BRA:ARG:IND\&hl=pt\&$\mathrm{dl}=\mathrm{pt} \# !$ ctype $=\mathrm{l} \&$ strail $=$ false $\& \mathrm{bcs}=\mathrm{d} \&$ nselm $=$ h\&met_y=ny_gdp_mktp_cd $\& s c a-$ le_y=lin\&ind_y=false\&rdim=region\&idim=country:BRA\&ifdim=region\&tstar$\mathrm{t}=1038448800000 \&$ tend $=1322445600000 \& \mathrm{hl}=\mathrm{pt} \& \mathrm{dl}=\mathrm{pt} \& \mathrm{ind}=\mathrm{false}$. Acesso em $28 / 11 / 2015$. 
se consolidaram como maioria nas eleições de 2014. O novo status do Congresso Nacional hoje é tão ou mais conservador do que os governantes ditadores do período pós-1964. Um levantamento do Departamento Intersindical de Assessoria Parlamentar (DIAP) mostra que o número de Deputados Federais ligados a causas sociais caiu, drasticamente. A proporção da frente sindical também foi reduzida quase à metade: de 83 para 46 parlamentares. Também houve um aumento considerável de policiais e militares eleitos, a chamada "bancada da bala". ${ }^{11}$

Diante da recessão econômica somada ao clima de instabilidade política e composição reacionária do Congresso, a flexibilização dos direitos dos trabalhadores é novamente apresentada como uma alternativa viável para a solução de problemas econômicos, políticos e mesmo sociais. Várias medidas flexibilizadoras são tomadas pelos três poderes da República. ${ }^{12}$ Diante dessa realidade, de um lado, o setor empresarial desponta como detentor de ampla representatividade no Congresso e forte influência política nos demais poderes; de outro, os sindicatos e os trabalhadores sentem-se acuados sob uma real ameaça de desemprego. Com isso, aqueles acabam avançando suas propostas e esses deixando de reivindicar por melhores condições de trabalho, passando a buscar tão-somente garantir a manutenção de seus postos de trabalho, "custe o que custar". ${ }^{3}$

11 Disponível em http://politica.estadao.com.br/noticias/eleicoes,congresso -eleito-e-o-mais-conservador-desde-1964-afirma-diap,1572528. Acesso em 28/11/2015.

12 Podemos citar aqui, apenas a título de exemplo, por parte do Poder Legislativo, a edição da lei dos motoristas, que autoriza jornada de trabalho de até 12 horas, pelo Poder Judiciário, a edição da Súmula 444 do TST, que reconhece a validade da mesma jornada, e, pelo Poder Executivo, a redução dos SeguroDesemprego, além da Medida Provisória n. 680, objeto do presente trabalho.

13 De acordo com o IBGE, a taxa de desemprego em outubro deste ano subiu 7,9\%, registrando o maior nível dos últimos oito anos. Disponível em ftp:// ftp.ibge.gov.br/Trabalho_e_Rendimento/Pesquisa_Mensal_de_Emprego/ fasciculo_indicadores_ibge/2015/pme_201510pubCompleta.pdf. Acesso em $28 / 11 / 2015$. 
Nesse campo de batalha ideológico, onde as diferentes classes digladiam, o Estado surge como um terceiro, nada neutro, que além de salvaguardar seus próprios interesses, tem de legitimar e defender os interesses do capital. Com a perspectiva de uma conjuntura econômica desfavorável e a necessidade de manter o capital e o lucro em alta, o setor empresarial volta a reivindicar a desoneração para o setor produtivo. Assim a classe trabalhadora, assumindo para si o risco da atividade econômica, acaba encarregada da incumbência de desonerar o "custo" da produção.

É neste cenário que, cinquenta anos depois da lei no 4.923, surge uma nova medida legislativa autorizando a redução dos salários como forma de solucionar mais uma crise do sistema capitalista de produção. A seguir, passaremos a analisar comparativamente os dois atos legislativos, a fim de constatar em que medida e em quais aspectos se assemelham e se diferenciam.

\section{COMPARAÇÃO DOS TEXTOS NORMATIVOS: LEI DI- TATORIAL VERSUS LEI DEMOCRÁTICA}

A irredutibilidade salarial é um direito fundamental do trabalhador, reconhecido expressamente pelo artigo 7ํ da Constituição Federal. Em medida que pode ser classificada como flexibilizadora, entretanto, a própria Constituição admite a redução dos salários mediante convenção ou acordo coletivo de trabalho. Obviamente, essa possibilidade, autorizada apenas de forma excepcional, encontra alguns limites. 0 primeiro desses limites decorre do próprio caput do artigo 7ํ da Constituição. Assim, a redução salarial somente será considerada constitucional, quando visar à melhoria da condição social dos trabalhadores. A pergunta que fica é a seguinte: em quais hipóteses e de que forma, a redução salarial pode realmente significar essa melhoria?

A resposta que logo surge é: para evitar um "mal maior". Assim, em épocas de crise econômica e sob a ameaça real de desemprego, seria razoável admitir a redução dos salários para 
garantir a preservação dos empregos. Resta investigar, então, de que forma essa redução deveria ocorrer, a fim de respeitar o texto constitucional.

Alguns possíveis contornos foram trazidos pela Lei $\mathrm{n}$ 응 13.189, de 19 de novembro de 2015, que decorreu da conversão da Medida Provisória 680, editada no mesmo ano. Como a alteração do ordenamento jurídico decorreu de uma medida provisória, a primeira questão que pode ser levantada diz respeito a sua constitucionalidade formal. Isso porque, nos termos do caput do Artigo 62 da Constituição, as medidas provisórias somente podem ser editadas "em caso de relevância e urgência". Poderse-ia argumentar que a presente crise econômico-financeira, de âmbito internacional, que vem afetando a economia brasileira, seria motivo suficiente para justificar a "medida". Ocorre que a possibilidade de redução salarial mediante correspondente redução da jornada de trabalho já era possível no Brasil, estando regulada por lei, pelo menos, desde 1965.

Autorizando a redução salarial mediante redução de jornada, a Lei no 4.923, de 23 de Dezembro de 1965, restou recepcionada pela Constituição de 1988, conforme entendimento majoritário tanto por parte da doutrina quanto da jurisprudência. Por essa razão, faz-se necessário uma análise comparativa entre a lei que autoriza a redução salarial no ano de 2015 (que daqui em diante passaremos a denominar lei democrática) e a de 1965 (que passará a ser por nós denominada como lei ditatorial).

Ambos os atos legislativos autorizam a redução dos salários dos trabalhadores, mediante redução equivalente da jornada de trabalho. Tais reduções, entretanto, encontram uma série de limitações, que não são idênticas numa e noutra lei. Em primeiro lugar, a lei ditatorial exige a comprovação de que, em face de conjuntura econômica, a empresa se encontre em condições que "recomendem" a redução da jornada normal ou do número de dias do trabalho. A medida deve ter prazo determinado, não ul- 
trapassando três meses, prorrogável, caso se mostre indispensável. A redução salarial deve ser procedida mediante prévio acordo com a entidade sindical representativa dos seus empregados ${ }^{14}$, homologado pela Delegacia Regional do Trabalho. A redução não pode ser superior a $25 \%$ do salário contratual, respeitado o salário-mínimo regional. Por fim, devem ser reduzidas proporcionalmente a remuneração e as gratificações de gerentes e diretores.

Muito embora o parágrafo $3^{\circ}$ do Artigo $2^{\circ}$ refira expressamente que "a redução de que trata o artigo não é considerada alteração unilateral do contrato individual de trabalho para os efeitos do disposto no art. 468 da Consolidação das Leis do Trabalho", é inegável que efetivamente se trata, não apenas da autorização de uma alteração contratual lesiva aos trabalhadores, mas de uma alteração que ocorre nos dois pilares fundamentais do contrato de trabalho: jornada e salário.

Fazemos uma pausa na análise do texto da lei para destacar, aqui, um expediente comum do discurso jurídico que visa legitimar a atuação exploratória do capital sobre a força de trabalho: para justificar tal exploração, o Direito tem de sustentar como uma "ficção jurídica" aquilo que todos sabemos não ser verdade. Nesse sentido, por exemplo, a Organização Internacional do Trabalho tem de sustentar, como seu primeiro princípio fundamental, que o trabalho humano não é uma mercadoria somente porque, no sistema capitalista de produção, uma mercadoria é justamente o que ele é. ${ }^{15}$

14 Nos termos do parágrafo primeiro do artigo $2^{\circ}$, o acordo coletivo de trabalho deverá necessariamente ser precedido de assembleia geral dos empregados diretamente interessados, sindicalizados ou não, que decidirão por maioria de votos, obedecidas as normas estatutárias. Conforme o parágrafo segundo do mesmo dispositivo legal, de duvidosa constitucionalidade, não havendo acordo, a questão seria submetida à Justiça do Trabalho.

15 No mesmo sentido do texto legal aqui referido, a Orientação Jurisprudencial n. 244 da SDI-I do TST sustenta não constituir alteração contratual a redução salarial do professor decorrente da redução de sua carga horária. 
Lembramos novamente daquela música da banda Legião Urbana, utilizada como epígrafe desse texto, que, não coincidentemente, leva o nome do ano da edição da lei aqui analisada. Lá pelas tantas, Renato Russo canta: "Cortaram meus braços, Cortaram minhas mãos, Cortaram minhas pernas, Num dia de verão, Num dia de verão, Num dia de verão..." Esse dia de verão bem poderia ser o dia 23 de Dezembro de $1965 .{ }^{16}$

Mais do que possibilitar uma mera alteração contratual, a Lei 4.923/65 simbolicamente representou verdadeiros cortes nos braços e pernas da classe trabalhadora brasileira. Ainda assim, esses cortes tinham limites bem definidos. Além dos requisitos já referidos, a redução salarial decorrente da redução da jornada de trabalho, de acordo com a lei ditatorial, gera alguns deveres, tanto para a empresa quanto para o Estado. Nos termos do seu artigo $3^{\circ}$, as empresas que obtiverem autorização para redução do salário com redução da jornada, não poderão, até seis meses depois do término desse regime, admitir novos empregados, antes de readmitirem os que tenham sido dispensados. ${ }^{17}$ Essa obrigação inviabiliza uma prática que vem sendo adotada atualmente pelas empresas, conforme denúncia dos próprios trabalhadores. Sob a alegação de dificuldades decorrentes da crise econômica, algumas empresas estão despedindo os empregados mais antigos para contratar novos, com salários consideravelmente menores; procedimento conhecido como "renovação da grade".

0 artigo $4^{\circ}$ da Lei 4.923/65 impede, ainda, que as empresas que reduzam a jornada de seus empregados o façam realizar ho-

16 Muito provavelmente a música não faz referência à lei em questão, mas a outras mutilações políticas, sociais e até mesmo corporais realizadas pela ditadura militar naquele ano e nos que se seguiram.

170 procedimento para readmissão, está descrito no parágrafo $1^{\text {ạ }}$ do artigo 3을 o empregador deverá notificar diretamente o empregado para reassumir o cargo, ou, por intermédio da sua entidade sindical, se desconhecida sua localização. Se, no prazo de oito dias, contado a partir da data do recebimento da notificação pelo empregado ou pelo órgão de classe, o empregado não se reapresentar para o emprego, poderá ser contratado outro empregado. 
ras extraordinárias, não apenas no período de redução da jornada, mas também nos seis meses subsequentes. Nada mais razoável. Não faria nenhum sentido a empresa aproveitar-se do momento de crise para reduzir os salários de seus empregados, mediante a redução proporcional da jornada e fazê-los, simultaneamente, ou imediatamente após essas reduções, realizarem horas extras. Ora, ou bem a demanda é baixa, em função da alegada crise, e não há necessidade de extrapolação da jornada; ou a prática da redução salarial deverá ser considerada como fraude à legislação trabalhista, ensejando o pagamento integral dos salários. Se faz necessário destacar que a realização de horas extras nessa situação (de redução salarial) se mostra ainda mais prejudicial ao trabalhador nos dias de hoje. Isso porque muitas vezes, essas horas extras sequer são pagas, mas compensadas por folgas. Prática que simplesmente desconsidera o direito fundamental, irrenunciável e inafastável (mesmo por norma coletiva) de que as horas extraordinárias valem, pelo menos, $50 \%$ a mais do que as horas normais.

Como já referido, pela aplicação da lei ditatorial, diferentemente do que ocorre com o PPE hoje, como se verá adiante, não são somente os trabalhadores que arcam com os custos da crise. A redução da jornada de trabalho, nesta hipótese, além de gerar deveres para o empregador, como já se viu, os gera também para o Estado. Nos termos do artigo 5o da lei, o Poder Executivo fica "autorizado" a instituir um plano de assistência aos trabalhadores que, após 120 dias consecutivos de serviço na mesma empresa, se encontrem desempregados ou venham a se desempregar, por dispensa sem justa causa ou por fechamento total ou parcial da empresa. É óbvio que essa autorização deve ser entendida como uma obrigação. Nos termos do parágrafo único do mesmo artigo, com redação dada pela Lei n. 5.737, de 1971, a assistência consistirá num auxílio em dinheiro, não excedente de $80 \%$ do salário-mínimo local devido, até o prazo máximo de 6 meses. 
Importa atribuir especial destaque a essa obrigação estatal (em tudo compatível com a Constituição Federal de 1988, especialmente em face de seu artigo $6^{\circ}$ ), nos tempos atuais que se apresentam, especialmente para os trabalhadores, ainda mais severos do que aqueles primeiros anos da ditadura. Veja-se, a esse respeito, apenas a título de exemplo, a perda das parcelas do Seguro-Desemprego em caso de lay-off. ${ }^{18}$

Não exageramos quando sustentamos que os tempos atuais são piores que aqueles do início da ditadura. Se a lei ditatorial importou um drástico corte ao principal direito dos trabalhadores, a lei democrática significa uma mutilação ainda maior. Sob a alegação de "proteção ao emprego", na verdade, são protegidos apenas as empresas e o Estado.

Em primeiro lugar, a nova lei não prevê aquela série de requisitos exigidos pela antiga para que ocorra a redução salarial. A intenção continua sendo a mesma, de salvar as empresas em período de crise econômico-financeira. Entretanto, os prejuízos aos trabalhadores se mostram ainda maiores. Começam pela forma de comprovação da dificuldade por que passa a empresa.

Em seu artigo 3ํㅡ a lei democrática estabelece que a dificuldade econômico-financeira da empresa deverá ser comprovada com base "no Indicador Líquido de Empregos - ILE, considerando-se nesta situação a empresa cujo ILE for igual ou inferior a $1 \%$, apurado com base nas informações disponíveis no Cadastro Geral de Empregados e Desempregados - CAGED, sendo que o ILE consiste no percentual representado pela diferença entre admissões e demissões acumulada nos doze meses anteriores ao da solicitação de adesão ao PPE, dividida pelo número de empregados no mês anterior ao início desse período". Ou seja, a nova lei

18 Lei n. 7.998/1990, Art. 8o-B: "Na hipótese prevista no § 50 do art. 476-A da Consolidação das Leis do Trabalho - CLT, as parcelas da bolsa de qualificação profissional que o empregado tiver recebido serão descontadas das parcelas do benefício do Seguro-Desemprego a que fizer jus, sendo-lhe garantido, no mínimo, o recebimento de uma parcela do Seguro-Desemprego." 
não apenas admite que as empresas despeçam seus empregados antes de aderir ao programa (algo que deveria ser considerado como fraude à sua aplicação), mas trata tais despedidas como um requisito para a sua adesão ao programa!

Essa fórmula utilizada para demonstrar a dificuldade econômico-financeira não estava prevista no texto original da medida provisória, tendo sido incluída no Projeto de Lei de Conversão. Em sua justificativa, o relator do projeto apela à "segurança jurídica”, argumentando que os requisitos para a adesão ao programa devem estar no texto da lei para que as empresas possam os implementar ${ }^{19}$. Argumenta, ainda, que, para poder aderir ao plano, a empresa deve demonstrar "de forma inequívoca, que tem demitido trabalhadores" ${ }^{20}$

Mas o principal objetivo do PPE não era justamente a preservação dos empregos?! A redução salarial não se justifica, desde 1965, justamente para evitar o "mal maior" das despedidas?! Aqui a nova lei apresenta uma de suas faces mais cruéis, podendo servir, agora oficialmente, de instrumento de redução de custos para empresas que, amparadas em um discurso de crise econômica, pretendam, por exemplo, reestruturar a sua planta ou simplesmente renovar o seu quadro de empregados para baratear ainda mais "o custo" com a mão-de-obra. Ao invés de proteger os trabalhadores contra a despedida, o programa de proteção ao emprego(?) acaba se revelando um verdadeiro incentivador de despedidas em massa.

${ }_{19}$ Mais uma vez chamamos a atenção, aqui, para o poder do discurso: a expressão "segurança jurídica" é muitas vezes utilizadas, não para sustentar a necessidade de observância de deveres e direitos, mas adquirindo um sentido de previsibilidade das condutas. Previsibilidade essa que atende muito mais a interesses econômicos, baseados em cálculos de meio para atingir determinados fins, do que a uma pretensão de Justiça. Em suma, segurança jurídica transforma-se em cálculo econômico. Não é por acaso que aumenta cada vez mais o estudo de "jurimetria" instituições jurídicas Brasil afora.

20 Disponível em http://www.camara.gov.br/proposicoesWeb/prop_mostrarintegra;jsessionid=035BF68DDB16E93556E4E94C7D541A31. proposicoesWeb2 codteor $=1396919 \&$ filename $=$ Tramitacao $-\mathrm{MPV}+680 / 2015$. Acesso em $13 / 10 / 2015$. 
Entretanto, caso não seja do interesse da empresa esvaziar seu quadro de empregados, o Estado lhe presta mais uma facilidade, autorizando a adesão ao programa mediante a apresentação de "outras informações relevantes para comprovar sua situação de dificuldade econômico-financeira", conforme estabelece o parágrafo terceiro do mesmo artigo terceiro.

Quanto ao prazo da redução salarial, a lei ditatorial também se revela mais benéfica do que a democrática. Enquanto aquela autoriza a redução por três meses, com possibilidade de prorrogação apenas caso essa se mostre indispensável; essa prevê a duração de seis meses, com possibilidade de sucessivas prorrogações até atingir um absurdo prazo de 24 meses! ${ }^{21}$

Como forma de "compensação", a lei democrática prevê a impossibilidade de dispensa arbitraria ou sem justa causa dos empregados que tiverem sua jornada de trabalho temporariamente reduzida enquanto vigorar a adesão ao programa e, após o seu término, durante o prazo equivalente a um terço do período de adesão. Ocorre que essa proteção se revela absolutamente insuficiente, tanto em sua forma quanto em sua extensão, conforme já tivemos oportunidade de sustentar em outro texto sobre o tema ${ }^{22}$.

Resta reduzida, ainda a necessidade de recontratação dos trabalhadores atingidos pelo programa. Pela lei ditatorial, as empresas se obrigam a readmitir o trabalhador despedido até seis meses após o término do regime de redução de jornada. De acordo com a lei democrática, esse período fica reduzido a um terço do período de adesão, que poderá significar apenas dois meses, caso não haja prorrogação. Resta facilitada, assim, a "renovação da grade" a que já nos referimos.

210 texto original da Medida Provisória previa o prazo de 12 meses, tendo sido estendido para 24 meses no Congresso Nacional.

22 AlmEIDA, Almiro Eduardo de. As falácias (e a verdade) do Programa de Proteção ao Emprego. LTr. Suplemento Trabalhista, v. 135, p. 695-700, 2015. 
Outra "inovação" é o limite da redução salarial. Como visto, pela lei ditatorial, a redução não poderia ser superior a $25 \%$ do salário contratual, respeitado o salário mínimo. A lei democrática autoriza a redução salarial em até 30\%, mostrando-se, assim, mais vantajosa para a empresa. ${ }^{23}$ Para "compensar", a nova lei prevê o pagamento ao trabalhador de uma parcela denominada "compensação pecuniária”. Essa parcela será paga em valor equivalente a $50 \%$ do valor da redução salarial. Essa pequena vantagem concedida aos trabalhadores em nada prejudica as empresas e, apenas aparentemente onera os cofres públicos. Isso porque a parcela deverá ser custeada pelo Fundo de Amparo ao Trabalhador - FAT, ou seja, por valores obtidos, ainda que em parte, pelos próprios trabalhadores e que, de qualquer forma, deveriam reverter a eles. Ao fim, são novamente os trabalhadores que pagam a conta da crise. Além disso, essa "compensação" é duplamente limitada: além de compensar apenas a metade dos prejuízos do trabalhador, não poderá ultrapassar o valor de $\mathrm{R} \$ 900,84$, correspondente a $65 \%$ do valor máximo da parcela do seguro-desemprego.

Quanto à natureza jurídica dessa "compensação", muito embora a lei trate da questão de forma muito limitada, entendemos ser salarial. Assim, seu valor deve ser considerado para o pagamento de todas as parcelas trabalhistas devidas ao trabalhador. Isso porque, em uma clara demonstração de preservação do (auto)interesse público, o Artigo 9o da lei é expresso ao determinar que a compensação pecuniária integra a remuneração para efeito de contribuição previdenciária e FGTS. Não sendo razoável sustentar que a lei democrática reconheça a natureza salarial da parcela apenas em relação aos valores devidos ao Estado, e não àqueles devidos diretamente ao trabalhador, a conclusão só pode ser de que os valores pagos a título de compensação pecuniária devam repercutir em férias com $1 / 3,13^{\circ}$ salários, etc.

${ }^{23}$ Resta mantido, entretanto, o limitador do valor do salário mínimo como máximo possível de redução salarial. 
Outra distinção importante das duas leis é o seu âmbito de abrangência. Enquanto a lei ditatorial dispõe que devam ser reduzidas proporcionalmente a remuneração e as gratificações de gerentes e diretores; a lei democrática nada refere a esse respeito, limitando-se a dispor que a redução salarial "deve abranger todos os empregados da empresa ou, no mínimo, os empregados de setor ou estabelecimento específico" (Artigo 5ํㅜ $§ 6^{\circ}$ ). Seria possível sustentar, assim, pela aplicação da lei democrática, que as remunerações e gratificações de gerentes e diretores restem preservadas, enquanto o salário dos demais trabalhadores, que já recebem menos, seja reduzido?

Quanto à impossibilidade de realização de horas extras, mais uma vez a lei democrática vem em prejuízo dos trabalhadores. Como se viu, a lei ditatorial impede a realização de horas extraordinárias, não apenas no período de redução da jornada, mas também nos seis meses subsequentes. As razões disso já foram apontadas. De acordo com a nova lei, somente fica impedida a realização de horas extras dos trabalhadores abrangidos pelo programa "durante o período de adesão" (Art. 6º,$\S 2^{\circ}$ ).

Resta mantida a necessidade de negociação coletiva, fazendo a nova lei referência expressa a "Acordo Coletivo de Trabalho Específico", instrumento que, no senso comum dos operadores do Direito do Trabalho, já vem sendo identificado como a possibilidade de supressão de direitos legais pela via da autonomia da vontade coletiva.

A propósito, é importante referir que a tentativa de fazer prevalecer o negociado sobre o legislado em prejuízo para o trabalhador - um espectro que assombra à classe trabalhador há vários anos -, foi novamente realizada pela Comissão Mista destinada a examinar e emitir parecer sobre a medida provisória no 680, tendo sido novamente rejeitada. 0 que apenas reforça nosso argumento de que tanto o Acordo Coletivo de Trabalho Específico que instituíra o PPE, quanto qualquer outra norma 
coletiva, somente será válida se efetivamente servir para melhorar as condições sociais dos trabalhadores.

Como se pode ver até aqui, cinquenta anos depois da edição de lei que autorizou a redução salarial durante o regime militar, um novo ato legislativo foi lançado com a mesma finalidade, em pleno regime democrático e por iniciativa de uma Presidente da República eleita pelo Partido (que se diz) dos Trabalhadores. Convertida em lei, a nova medida conseguiu ser ainda mais prejudicial aos trabalhadores do que o ato ditatorial, em vários pontos.

0 texto da nova lei, entretanto, não tem o condão de revogar os dispositivos mais favoráveis (ou deveríamos dizer menos prejudiciais?) da lei de 1965. No que for pior do que a lei ditatorial, a lei democrática não pode ser aplicável, seja por ser inconstitucional (por afrontar o caput do artigo 7ํㅡ, no que não visa a melhoria da condição social dos trabalhadores), seja pela necessidade da aplicação da norma mais favorável. A propósito, afastado o critério do conglobamento, cuja implementação também foi tentada pela Comissão Mista do Projeto de Lei de Conversão do PPE, há de se considerar como acolhido no Brasil o critério da acumulação ou soma. Assim, devem ser aplicados somente os dispositivos mais favoráveis de cada norma.

Por fim, quanto ao Estado, além de não prever aquela assistência de que trata a lei ditatorial, a democrática, não apenas resguarda expressamente as parcelas trabalhistas e previdenciárias a ele devidas, como já referido, mas condiciona a adesão da empresa ao programa à comprovação da "regularidade fiscal, previdenciária e relativa ao FGTS". Resta novamente resguardado o (auto)interesse público.

Como sustentamos anteriormente em texto aqui já referido, o Programa de Proteção ao Emprego acaba se revelando um verdadeiro Programa de Proteção à Empresa. Enquanto essa sai economicamente fortalecida e o Estado fica com suas economias preservadas, o trabalhador, a quem o programa deveria se des- 
tinar a proteger, é quem acaba pagando, mais uma vez, a conta da crise.

Voltando àquela música, se em 1965 cortaram os membros dos trabalhadores em um dia de verão; hoje, cinquenta anos depois, em um dia de inverno, mutilam o que resta de suas forças. Um dia de inverno que parece bem representar o atual momento por que passa a classe trabalhadora no Brasil.

\section{CONCLUSÃO}

Cinquenta anos separam as Leis $\mathrm{n}-4.923$ e $\mathrm{n}$ o 13.189. Como a história nunca se repete de forma exatamente igual, o momento atual guarda semelhanças e distinções com aquele que marcou o início da ditadura militar no Brasil. A economia, em crise, passa por um momento totalmente diferente daquele que ficou conhecido como parte dos anos dourados do capitalismo. A política encontra-se novamente conturbada, porém, por razões bem distintas da "ameaça comunista" dos anos de guerra fria. Já os movimentos sociais ocorridos em junho de 2013, assim como aqueles de cinquenta anos atrás, parecem ter sido sucedidos por uma forte reação conservadora.

É possível dizer que, assim como ocorreu há meio século, mais uma vez o Direito do Trabalho está passando por um grave momento; talvez o atual seja ainda pior do que o anterior. Por um lado, os aplicadores do Direito do Trabalho não conseguem fazer valer os mais elementares direitos dos trabalhadores, como por exemplo, a vedação da despedida arbitrária ou sem justa causa prevista expressamente na Constituição. Por outro, esses mesmos aplicadores consideram recepcionada uma lei que, feita durante a ditadura militar, muito pouco se coaduna com os preceitos constitucionais democráticos. Pior do que isso, sob a justificativa de "proteger os empregos" daqueles trabalhadores cuja proteção contra a despedida não se reconhece, é editada uma nova lei, que consegue ser ainda pior do que a ditatorial. No presente artigo, 
pretendemos ter destacado alguns desses dispositivos da nova lei que, por serem prejudiciais aos trabalhadores e significarem um retrocesso de sua condição social, não poderão ser aplicados.

Meio século não pode ser simplesmente desconsiderado. Ou avançamos em relação aos atos praticados contra os direitos sociais em um dos períodos mais tristes de nossa história, ou de nada terá adiantado toda a luta pela democracia: a esperança acabará transformando-se, novamente, em maldição.

\section{REFERÊNCIAS}

FASUTO, Boris. História concisa do Brasil. 1 ed. São Paulo: Universidade de São Paulo, 2002.

. O Brasil Republicano: economia e cultura (1930-1964). 3 ed. Rio de Janeiro: Bertrand Brasil, 1995.

MATOS, Marcelo Badaró. Trabalhadores e sindicatos no Brasil. 1 ed. São Paulo Expressão Popular, 2009.

MANDEL, Ernest. A crise do capital: os fatos e sua interpretação marxista. São Paulo: Ensaio; Campinas, SP: Editora da Universidade Estadual de Campinas, 1990, p. 9.

http://www.camara.gov.br/proposicoesWeb/prop_mostrarintegra;jse ssionid=035BF68DDB16E93556E4E94C7D541A31. proposicoesWeb2? codteor $=1396919 \&$ filename $=$ Tramitacao-MPV+680/2015.

https://www.google.com.br/publicdata/ explore?ds=d5bncppjof8f9_\&met_y=ny_gdp_mktp_cd\&idim=countr $\mathrm{y}:$ BRA:ARG:IND\&hl=pt\&dl=pt\#!ctype $=\mathrm{l} \&$ strail=false \&bcs $=\mathrm{d} \&$ nselm =h\&met_y=ny_gdp_mktp_cd\&scale_y=lin\&ind_y=false\&rdim=region \&idim=country:BRA\&ifdim=region\&tstart $=-286927200000 \&$ tend $=-$ $160696800000 \& \mathrm{hl}=\mathrm{pt} \& \mathrm{dl}=\mathrm{pt} \& \mathrm{ind}=$ false.

https://www.google.com.br/publicdata/ explore?ds=d5bncppjof8f9_\&met_y=ny_gdp_mktp_cd\&idim=country:B RA:ARG:IND\&hl=pt\&dl=pt\#!ctype $=1 \&$ strail $=$ false $\& b c s=d \& n s e l m=h \& m$ et_y=ny_gdp_mktp_cd\&scale_y=lin\&ind_y=false\&rdim=region\&idim $=c$ ountry:BRA\&ifdim=region\&tstart $=1038448800000 \&$ tend $=13224456$ $00000 \& \mathrm{hl}=\mathrm{pt} \& \mathrm{dl}=\mathrm{pt} \&$ ind $=$ false. 
Revista do Curso de Direito do Centro Universitário Metodista - IPA

http://politica.estadao.com.br/noticias/eleicoes,congresso-eleito-e-o-mais-conservador-desde-1964-afirma-diap,1572528.

ftp://ftp.ibge.gov.br/Trabalho_e_Rendimento/Pesquisa_Mensal_de_Emprego/fasciculo_indicadores_ibge/2015/pme_201510pubCompleta.pdf. 